\title{
GEORG SIMMEL E A CRÍTICA À OBJETIVIDADE DO CONHECIMENTO
}

\author{
Georg Simmel and the criticism to the objectivity of knowledge
}

\author{
Murilo Canella'
}

\begin{abstract}
Resumo
Este artigo propõe a análise da crítica à objetividade do conhecimento efetuada por Georg Simmel. Dessa delimitação deriva a densa síntese teórica condensada nesse tema, visto ele se apresentar de forma fragmentada - mas não negligenciada - ao longo de sua obra. A temática da crítica à objetividade do conhecimento perpassa o jovem e o maduro Simmel; o eixo teórico desloca-se do domínio metaconceitual do qual a sociologia formal nutre-se, à esfera metodológica do relacionismo e aos processos empíricos simultâneos que concatenam a realidade social. Este estudo pretende analisar a crítica referida, num primeiro momento, e, posteriormente, intenta relacionar e demonstrar o vínculo conceitual existente entre a crítica e outros dois complexos conceituais basais em Simmel, a cultura e 0 individualismo. A metodologia refere-se, portanto, à análise da crítica à objetividade do conhecimento sistematizada no texto tardio A lei individual, publicado em 1913 na revista Logos, e sua relação teórica substancial com o domínio da cultura e sua expressão no individualismo.
\end{abstract}

Palavras-chave: Georg Simmel; Cultura; Modernidade; Individualismo; Crise.

\begin{abstract}
This article proposes the analysis of the criticism to the objectivity of the knowledge realized by Georg Simmel. From this delimitation derives the problematic about the condensed theoretical synthesis in this theme, since it presents itself in a fragmented way throughout his work - but not neglected. The critique of the objectivity of knowledge permeates the young and mature Simmel; the theoretical axis shifts from the metaconceptual domain from which formal sociology is nourished, to the methodological sphere of relationism and to the simultaneous empirical processes that link social reality. This study intends to analyse the critique referred at first, and then tries to relate and demonstrate the conceptual link between this critique and two other basic conceptual complexes in Simmel, culture and individualism. The methodology refers to the understanding of the critique of the objectivity of knowledge, systematized in the late text The individual law, published in 1913 in the journal Logos, and its theoretical relation with the domain of culture and its expression in individualism.
\end{abstract}

Keywords: Georg Simmel; Culture; Modernity; Individualism; Crisis. \footnotetext{
1 Universidade Estadual Paulista Júlio de Mesquita Filho (UNESP). Email:
murilo_canella@hotmail.com.
} 


\section{Pela justificação da relação: a crítica à objetividade do conhecimento como uma introdução a Simmel}

Uma forma elementar de compreender a crítica à objetividade do conhecimento efetuada por Simmel é apreender algumas das negativas recepções críticas de sua obra até o presente. Três eixos temáticos - que não pretendem ser um guia cronológico, mas tão só uma síntese temática - da crítica podem ser traçados. Considerou-se (WIESE, 1932; ARON, 1967; COLLINS, 1994; FRISBY, 2013) Simmel um esteta e um teórico inconsistente; o argumento é extraído de sua caricaturização enquanto um literato precoce, cujo raio de ação do pensamento, analogamente a sua metodologia, consiste em saltar e flanar entre distintos tópicos, sem um projeto teórico consistente. Considerou-se também (COSER, 1956; FREUND, 1981; SPYKMAN, 2004) Simmel um teórico inconstante, segundo uma equivocada tripartição de sua obra, enquadrando-a em uma disposição evolucionária iniciada com uma fase de orientação darwinista, spenceriana e positivista, seguida de uma guinada de matriz neokantiana, e finda com uma filosofia da vida de viés bergsoniano. Estrutura-se, a partir daí, uma visão crítica mais sofisticada que a anterior, de importância figurativa; porém, ela encaixa o complexo e multifacetado pensamento de Simmel em um sentido artificial alheio à matéria de seu pensamento, segundo o qual impera como substância a dispersão de temáticas ao longo das décadas, o pensamento assistemático, preocupado com questões filosóficas alheias à empiria, e a falta de substancialidade teórica. Um terceiro viés crítico (SOROKIN, 1928; WATSON, 1985) identifica Simmel a um metafísico e fenomenologista, cuja artificialidade dos trabalhos é comprovada pela ausência de anotações de campo, de notas de rodapé, de estatísticas, dados sistematicamente coletados e referências bibliográficas ${ }^{2}$.

A crítica do crítico Simmel padeceu, pelos limites cognitivos impostos pelo tempo, de um monoperspectivismo analítico e de um preciosismo teórico que, objetiva e virtualmente, não se realizam nos próprios escritos de

\footnotetext{
2 Talvez essa visão crítica intensifique-se com o ambivalente "testamento" de Simmel: "Sei que irei morrer sem herdeiros espirituais (e é bom que seja assim). Meu espólio é como uma herança em dinheiro vivo, que é dividida entre muitos herdeiros: cada um converte a sua parte em alguma aquisição de acordo com a sua natureza, de modo que não se pode enxergar a sua proveniência daquele espólio". (SIMMEL, 2011, p.14, grifo do autor).
} 
Simmel. O trato crítico afeito a um flaneur, a um esteta e literato precoce, a um fenomenologista e metafísico e a um intelectual símbolo de uma irresponsável miscelânea teórica, rui mediante simples argumentos (BACKAUS, 1998; LEVINE, 1971, 1991, 2014, 2015). A primeira refutação dessa crítica é a consistência do método relacional de Simmel. Ele se apresenta de forma coerente ao longo de sua obra, atravessando as caricatas e equivocadas fases darwinista, neokantiana e bergsoniana. O relacionismo é tanto um domínio metaconceitual - visto a insistência de Simmel (2011, p. 47) na necessidade contínua de um trabalho transempírico, objetivado devido à dupla natureza de toda disciplina, composta por assunções epistemológicas que direcionam análises empíricas, presentes no fundamento mesmo de cada disciplina, e, além delas, encontra-se o complexo contexto humano e histórico ao qual ela está relacionada, na esteia de questões insolúveis, mas que a subjetividade humana tampouco não pode parar de se indagar -, quanto um conceito metodológico central na objetivação das proposições da sociologia formal. Enquanto método, o relacionismo consiste em selecionar e excetuar idealmente algum fenômeno delimitado e finito do mundo em seu fluxo vital, examinar a multiplicidade de elementos que compõem essa unidade, e averiguar a causa de sua coerência, revelando, assim, sua forma - recurso teórico sustentado discursivamente por explanações, analogias e metáforas.

A metafísica, outro eixo temático crítico, integra o domínio metaconceitual da sociologia formal. A metafísica de Simmel, como pontuado cirurgicamente por Kracauer (2009, p. 251), é o ponto de incursão ao "mundo de Simmel", no qual a realização do conhecimento, da sociabilidade e da cultura somente é possível em seus próprios termos. Isso possui dupla consequência: o "mundo de Simmel" é constituído pela delimitação de um universo de polaridades opostas que estrutura as condições do pensamento concomitantemente ao processo de determinação da gramática social. As dualidades concatenam-se através da interação - daí a feliz expressão de Fréderic Vanderberghe (2009, p. 72), dualismo heurístico -, um metaconceito que rege os domínios vital, empírico e cognoscitivo. Nele imiscui-se a dinâmica processual dos polos constitutivos da existência (anímica e 
objetiva), caracterizados pela dualidade e mutualidade da interação, o que, no desproporcional intercâmbio entre a vitalidade da vida e as formas do conhecimento - pela estrutura dual das interações, e também pelo descompasso elementar imperante entre vida e forma - enseja uma dialética cultural sem síntese.

Deriva daí a estrutura formal da existência ser a realidade na qual os elementos procuram-se, completam-se e se repelem uns aos outros. Nesse processo, tanto a dissociação dos elementos como sua síntese em unidades de significado coletivas é uma condição e possibilidade da interação. Mesmo em potenciais situações nas quais a polaridade distinta dos elementos leva a autodestruição de ambos ou a destruição parcial de um, configura-se uma forma geral de interação que engloba os polos da vida em uma síntese maior. A centralidade da questão dirige-se, portanto, ao conceito de dualismo, encarado não somente como uma forma metodológica de se alcançar o parcial conhecimento da realidade, tampouco como uma forma epistemológica de estruturar as condições do conhecimento; essas duas instâncias amalgamam-se tornando o dualismo tanto a condição objetiva quanto cognoscitiva da interação.

Também, o particular mundo de Simmel é caracterizado por uma concepção cósmica individual - pese a heterogênea nutrição teórica de seu pensamento - e marcada por pontuais intuições, o que o aproxima de um crítico literário e o afasta da aura de um irresponsável literato precoce. Podese dizer que Simmel intentou - e, inevitavelmente, cometeu equívocos - um sintético pensamento idiossincrático acerca da vida: o eternamente frustrado anseio pela totalidade é uma vocação do grande crítico. A síntese desse embate crítico pode ser compreendida na lapidar proposição de Leopoldo Waizbort (2011, p. 78): as críticas que em quase um século minimizaram e depreciaram a importância e o impacto do pensamento de Simmel sob as tradições de pensamento social dirigiam-se às proposições de seu pensamento ou à sua forma teórica (ensaio)? A crítica à objetividade do conhecimento revela, contextualizada conjuntamente às inconsistências críticas citadas, um foco objetivo de análise ao revelar os complexos nexos da obra de Simmel. Também, a referida crítica é simbólica, pois é no mínimo 
curiosa a recepção crítica de Simmel nos termos de um flaneur sociológico, um autor cuja base do pensamento é uma profunda crítica à natureza do conhecimento.

\section{A crítica em questão}

A lei individual é um texto pouco analisado. Simmel o concebeu aos cinquenta e cinco anos, cinco anos antes de sua morte, o que por si revela a maturidade intelectual e a síntese teórica nele condensadas.

O contexto intelectual de Simmel era o da crise filosófica alemã do início do século XX (GROETHUYSEN, 1926; WIESE, 1932; FRÉULER, 1997; MOSSE, 2007), manifesta no descrédito em relação aos grandes sistemas e no abandono do monolitismo hegeliano perdurante no século XIX, além de uma substancial crítica ao neokantismo. Essa crise filosófica, acompanhada de um contexto social empírico conflituoso (HOBSBAWM, 1995, 2013; POLANYI, 1980), significou o fim de uma maneira de se fazer filosofia. O desapego com a totalidade, sustentado pelo rechaço a conceitos que descrevam mecanicamente a sociedade, é um traço característico de Simmel que se intensifica nos anos finais de sua vida, mas com uma exceção. A totalidade considerada por Simmel é a vida. A vida é a antítese da forma, porém, uma entidade somente pode ser descrita conceitualmente no interior de alguma forma. Daí decorre ser a vida algo vago e logicamente impreciso, pois ela precede ou transcende todas as formas, e defini-la conceitualmente é negar sua essência. Apenas diretamente a vida pode tornar-se consciente de si, por seu dinamismo, e não através de conceitos intermediários, coincidindo com o reino das formas.

Em A lei individual, Simmel (2003) faz uma análise acerca dos princípios da ética a partir da crítica do imperativo categórico kantiano e seu arcabouço racionalista. Porém, várias temáticas relacionam-se à medida que Simmel intenta dar sólidas bases à sua teoria derivada da legitimação da vida a partir de seu polo individual - mas não um polo anarquicamente heterônomo, visto o fluxo objetivo e inter-subjetivo que transpassa os indivíduos -, trabalhando na vinculação conceitual da individualidade à objetividade e na ligação da ética ao dinamismo interno da vida - que, por 
seu caráter vital, encerra-se como totalidade em cada instante -, legitimando assim um dever moral atrelado à vitalidade da vida individual, cujas disposições normativas derivem do interior próprio da vida, e não de um esquema artificial idealmente pré-ordenado.

Simmel estrutura sua crítica ao imperativo categórico de Kant (1950, 2004, 2008) partindo da vinculação conceitual entre lei e universalidade. Em sua base está o caráter (KANT, 2008) individual da realidade psíquica: a variedade multifacetada das impressões sensiveis compõe-se em unidades, as quais possuem por base um intelecto cuja essência é também uma unidade, transformando assim o eu em portador e construtor da objetividade. Daí a síntese: “[...] se todo o real é individual, o ideal deve ser universal. Se todo o individual é somente real, ele não pode ser simultaneamente situado acima da realidade como ocorre com a exigência ideal de uma lei" (SIMMEL, 2003, p. 34). O domínio ético aproxima-se da lei universal, pois seu pressuposto ideal não pode, na perspectiva kantiana, ser identificado ao domínio individual. O imperativo categórico tensiona a relação entre o dever e a universalidade da lei na medida em que o dever, um fato da existência social, provém de um esquema ideal sustentado por exigências e viabilidades ideais e previamente fixado numa ordem determinada temporal e racionalmente.

A lei, portanto, é, por ela, universal segundo seu próprio conceito, pois todo o eticamente preceptivo ou proibitivo deve originar-se de conteúdos que subsistem por si mesmos em virtude de sua lógica autônoma. Nessa perspectiva, pareia-se a obrigação moral do dever à validez universal, ou lógico-conceitual, do conteúdo da ação, concretizando uma cosmovisão racionalista, visto ser, nessa perspectiva, a razão o cerne radical da realidade, sua estrutura constituinte. Corolário, o imperativo categórico unese à teleologia - o domínio que, através da razão, reduz o dever moral a meio em relação a um fim - e à universalidade. Simmel tece uma dupla crítica a essa perspectiva.

\footnotetext{
3 Ao significado jurídico de lei acrescenta-se o significado de um princípio substancial e normativo capaz de significar simbolicamente, organizando parcialmente instituições sociais e biografias individuais.
} 
Primeiramente, o diagnóstico de que a lei universal e o imperativo categórico são estranhos à forma essencial da vida - um fluxo contínuo inapreensivel em sua totalidade pela razão. Seus problemas decorrem da teorética racionalista: os predicados de possiveis sujeitos podem ser tomados separadamente em relação a estes e representados como conteúdos logicamente autônomos. A pergunta acerca do sentido de uma ação é separada do sujeito que a sustenta, de forma que, a partir da resposta dada a essa pergunta, julga-se acerca da legitimidade ou ilegitimidade moral da relação desta ação com aquele sujeito. Em segundo lugar, Simmel aponta à estrutura do racionalismo kantiano: o modelo de lei adotada por Kant deriva da ciência natural, cuja substância é a formulação de um transcurso, e do direito, no qual a lei ordena desde si como deve transcorrer uma ação. $\mathrm{O}$ imperativo categórico é constituído, portanto, pela estrutura lógica de uma lei natural de procedência mecanicista concomitantemente à determinação de um princípio jurídico. A substancial crítica de Simmel a essa dupla perspectiva é a de que o que emana da razão não pode se converter em função estrita da vida real e sua dimensão ética - por sua vez uma unidade , pois a razão é somente uma parte constituinte dessa totalidade.

A contraposição conceitual de Simmel a essa perspectiva segue o viés vitalista: a realidade é complexa demais para ser traduzida objetiva e cabalmente em conceitos. Origina-se uma reflexão gnoseológica crítica manifesta no universo metafísico e metaconceitual, dois dos principais componentes da sociologia formal - o ponto de crítica principal deste artigo. Nesta temática, a totalidade conceitual com a qual Simmel trabalha é o conceito de vida. A vida nos aparece como a condição vital na qual a realidade é configurada através da continuidade vital de eventos e processos, indissociáveis entre si, guardando uma lenta e recíproca confluência, alheia, por sua vez, às diferenciações objetivas do conhecimento - a vida é uma totalidade sob a qual é contraditório estabelecer limites. Dada a complexidade da vida, o conhecimento objetivo (em si uma das maiores realizações do universo, pois através do cérebro humano o universo autocontempla-se) opera pela secção dos contínuos processos, pelo enquadramento do círculo da complexidade da vitalidade em conceitos e 
categorias ordenadas lógica e temporalmente, constituídos como conteúdos singularizáveis.

Portanto, o conhecimento objetivo é um processo artificial que constitui uma ponte - palavra importantíssima em Simmel (2011b, p. 27) entre a vitalidade e a objetividade, por sua vez apreendida segundo uma discrepância substancial. Porém, a objetividade a duras penas construída através do conhecimento não é subestimada por ele; ao contrário, ao expor o frágil caráter objetivo dos conceitos, Simmel intenta destacar a natureza distinta imperante entre a forma de vivenciar e a conceitualidade. O processo artificial do conhecimento comporta tanto uma discrepância qualitativa em relação à dinâmica da vida quanto uma alteração de tipo e forma (SIMMEL, 2003, p. 42). Submeter o real aos conceitos significa cooptar em pluralidades categoriais abruptamente separadas a deslizante gradação e a ininterrupta correlatividade que se dá em e entre as coisas, objetivando um processo que extrai os conteúdos práticos da forma vivenciada e os transpõem a uma conceitualidade autônoma - estrutura-se a comunhão do processo anímico com a categoria, que não lhe é inerente, de conteúdos singularizáveis, separados segundo diferenciações lógicas, objetivando um processo de diferenciação infinito entre os constructos singularizáveis e relacionáveis do conhecimento. Portanto, a crítica de Simmel ao conhecimento objetivo e à objetividade do conhecimento pode ser encarada como um princípio reflexivo - tanto no sentido de reflexão acerca das bases do conhecimento, quanto no sentido contemporâneo (BECK, 2012, p. 18; GIDDENS, 2012, p. 288) que conecta as prerrogativas do conhecimento a uma constelação autocrítica concernente ao autoenfrentamento dos constructos objetivos na arena social - que engloba o universo metaconceitual na tentativa de exemplificar e frisar tanto a natureza distinta entre a vitalidade e a conceitualidade, quanto um ponto de incursão na complexidade artificialmente construída através do conhecimento. A crítica à objetividade do conhecimento provém de sua perspectiva racionalista que, ao direcionar o sentido da realidade através de conceitos e categorias, de forma a lhes garantir uma ordem lógica, transforma a vida, com sua plena vitalidade, em um esquema derivado de 
uma fonte ausente daquela primeva vitalidade - ou seja, a irrupção da tendência lógica em um âmbito alheio a ela.

Figura outro ponto de crítica. O fragmento extraído do decurso vital da vida, por mediação do conceito, é tão pertencente à continuidade desse mesmo decurso como qualquer outro segmento que transcorra entre dois momentos temporais quaisquer. Daí o conteúdo do conceito universal que designa uma coisa concreta incluir somente certas partes, aspectos e determinações da coisa, deixando infinitas outras, em si mesmas totalidades, fora do âmbito conceitual. O conceito, devido a sua natureza parcial e fragmentária, é válido para a totalidade e a unidade da coisa, inclusive aquelas determinações não relacionadas diretamente a ele. Simmel concebe uma curiosa analogia:

[...] o conceito é, a maneira de um esqueleto, um esquema ideal no qual se inserem todos os componentes ou qualificações individuais, uma forma interna que mantém unidos todos os elementos abarcados pelo âmbito da coisa. O conceito não é somente o mínimo lógico da coisa enquanto contém aqueles elementos que a coisa há de mostrar para que seja fixada com um determinado significado. Tem, em decorrência disso, um sentido funcional de impor também uma forma aos elementos restantes, ou mais exatamente: a todos os elementos reais do ente, forma pela qual podem circular os variadíssimos componentes da existência. (SIMMEL, 2003, p. 35, grifo nosso).

Os conceitos são, em virtude de sua natureza, esquemas formais e funcionais que se agrupam, concatenando uma totalidade conceitual de casos singularizados, desprovidos de dinâmica vital, inseridos em um quadro quantitativa e qualitativamente distinto da vitalidade, objetivados segundo caracteres ideais previamente elegidos. A crítica efetuada por Simmel possui um caráter analitico e explanatório - dois fundamentais recursos metodológicos da sociologia formal - visando elucidar criticamente, apegando-se à vitalidade da vida, as bases do conhecimento, afastando-a, portanto, de uma visão crítica estritamente desconstrutivista. Também, a referida crítica assume um caráter heurístico, pois estrutura-se uma primeva distinção entre a vida e suas subsequentes formas, ou seja, a diferenciação entre conteúdos e circunstâncias vitais.

O que posteriormente Simmel (2004, 2006b, 2010b, 2011, 2011d) caracterizou como o desenvolvimento de mundos distintos na modernidade 
pelo processo de diferenciação social pode ser entrevisto nessa diferenciação substancial entre os processos vitais da realidade e a percepção e representação que fazem deles os sujeitos. A discrepância e inadequação quantitativa e qualitativa existente entre a forma de vivenciar e a conceitualidade não é por Simmel tomada como uma panaceia; é, antes, a pré-condição de um conhecimento - este constructo que se firma sob a areia - que lida de forma reflexiva com suas próprias limitações. O sentido substancial dessa crítica é o de demarcar uma diferenciação entre a vitalidade da vida e as formas e conteúdos culturais dela advindos e nutridos pela atividade anímica. A crítica, portanto, não assume um rigor tratadístico, mas sim uma incursão ensaística (ADORNO, 2008, p. 16), criticamente munida, aquele ideal e inalcançável ponto no qual a vida desdobra-se sobre si mesma e adquire um status diferenciado formalmente. Exposta a crítica, a análise dirigir-se-á ao complexo categorial da cultura e sua relação teórica com a referida crítica e, posteriormente, à relação da tensão ontológica que, por sua vez, erige-se como condição elementar e contextual da vida humana - do dever expressa no dualismo do individualismo.

\section{A cultura e a crise: a diferenciação cultural e a lógica da crítica à objetividade do conhecimento}

A cultura em Simmel aponta a uma sintese teórica cujas nuances devem ser distinguidas. É necessário, primeiramente, uma definição conceitual em linhas gerais de cultura, visto ela ter sofrido reelaborações ao longo da vida de Simmel. A cultura é um complexo no qual contorno teórico e conceito coexistem. O corpo teórico aborda um complexo categorial orientado por dinâmicas inter-relacionadas; enquanto conceito, descreve os conflitos existentes entre vida e forma (nos quais imiscuem-se variados conflitos no tecido social) (SIMMEL, 2004, 2006b, 2007, 2008).

Três diferentes tratos conceituais das teorias da cultura em Simmel podem ser depreendidos (PASTI, 2012, p. 20). Num primeiro momento conceitual - o jovem Simmel preocupado com a diferenciação social -, a cultura em si não é o objeto central; ela está submetida à discussão acerca do papel do dinheiro na modernidade. Estrutura-se o estudo dos efeitos psicológicos da difusão da economia monetária no tecido social, e desses 
efeitos decorre a discussão sobre o papel dos meios - uma vez que o dinheiro torna-se o meio por excelência, atuante como mediador universal necessário à obtenção dos mais díspares fins. Os meios mobilizam-se pela translação ao redor de fins mais complexos: a cultura aparece aí tematizada como o resultado e o aprofundamento dessas séries teleológicas. Num segundo momento - exemplificando a busca conceitual de Simmel acerca do que é feita a história -, corolário dessas séries teleológicas, Simmel concebe uma divisão categorial na unicidade da cultura.

A cultura objetiva compreende as variadas obras paridas pela alma em seu processo de objetivação: a primeva subjetividade encontra, pela carência de meios inerentes ao seu objetivo desenvolvimento, existência objetiva através da cristalização do fluxo anímico vital em formas objetivas. A cultura subjetiva consiste na alma singular, que se exterioriza, pela carência de meios e pelo ideal de cultivo em formações objetivas, para posteriormente ressubjetivá-las. Esse cultivo é ameaçado na modernidade, pois tanto as cadeias teleológicas quanto a cisão e a complementaridade entre as duas formas de cultura interpõem labirinticos meios, nos quais objetiva-se uma dialética cultural sem síntese. E, no terceiro e último momento - no qual Simmel estrutura uma análise compreensiva, cuja substância remete ao inexorável e insolúvel conflito entre a vitalidade da vida e a estabilidade atemporal das formas -, caracteriza-se a tragédia da cultura: do processo mesmo de cultivo - da subjetividade objetivada à objetividade ressubjetivada - nascem forças protagonistas de um perpétuo desequilíbrio entre as esferas.

Esse desequilíbrio é uma condição imanente, vista a distinção qualitativa e quantitativa imperante entre vida e forma, o que transforma a adjetiva tragédia da cultura em uma cultura substancial e elementarmente trágica. Mas considerado seu caráter trágico, ele provém do fato de as forças opressoras voltadas contra o sujeito humano nascerem da subjetividade do próprio sujeito. Este é um movimento comum a todas as esferas da cultura ou seja, a existência autônoma e/ou autorreferenciada das concreções objetivas, portanto, da cultura objetiva. Porém, na modernidade o acirramento dessa separação é condicionado por alguns fatores estruturais e cognitivos, como o advento da economia monetarizada, o aprofundamento e 
a radicalização da divisão do trabalho e o recrudescimento da racionalidade calculista - fatores que atuam, segundo Simmel (2011d), em uma complementaridade interacional, alheia a determinismos unilaterais. Em linhas gerais, a cultura surge no aprofundamento das cadeias teleológicas de sentido, seguida da bipartição entre sua esfera objetiva e subjetiva para, posteriormente, concretizar-se na ideia de uma totalidade essencialmente trágica, atuante na conformação da vida, em sua natureza de fluxo contínuo e vital, dentro do universo objetivo da forma. Se se preferir uma fórmula para a cultura, equacionando desproporcionalmente sujeito e objeto, ela pode ser considerada nos seguintes termos: as energias anímicas subjetivas alcançam uma forma objetiva, independente do processo vital do criador; essa forma, por sua vez, é reinserida no processo de vida subjetivo de forma que leve o sujeito à perfeição acabada de seu ser central.

A tensão primordial considerada por Simmel está na relação entre sujeito e objeto (SIMMEL, 1961, p. 78). À medida que a vida avança para além do nível puramente biológico em direção ao nível do espírito e, posteriormente, quando este avança em direção à cultura, emerge um elementar conflito interno. O espírito impulsiona incontáveis criações que seguem existindo com uma autonomia particular tanto da alma que primevamente as criou como daquelas outras que as recebem ou as recusam. Concatena-se uma tensão entre a forma da vida subjetiva, animicamente infatigável, mas temporalmente finita, e seus conteúdos que, uma vez objetivados, são estáticos, mas possuem uma validade atemporal instaura-se, portanto, uma discrepância qualitativa e quantitativa entre os processos vitais da vida, em seu ininterrupto fluir, e as formas objetivas alcançadas por estes processos através da psique humana. Outro fator de ordem temporal é fundamental na concreção da cultura em contraposição à natureza: à medida que o inanimado possui o contexto das configurações objetivas imediatas de um dado ecossistema, o ser do homem estende-se ao passado e ao futuro. Seus movimentos anímicos, como a vontade, o dever, a vocação e a esperança constituem a continuação espiritual da determinação fundamental da vida: conter seu futuro em seu presente. 
Essa configuração da vida humana e seu processo anímico que envolve a existência virtual de possibilidades de desenvolvimento é o pressuposto do ideal de cultivo. Ele pressupõe ${ }^{4}$ o envolvimento de uma formação objetiva no processo evolutivo da alma subjetiva, que, por sua vez, não dispõe, naturalmente, de tais formações como um meio e estágio de sua perfeição que volta a si mesma. O processo do cultivo inicia-se quando os saberes e capacidades - conteúdos dos constructos culturais objetivos servem ao desenvolvimento da centralidade anímica (SIMMEL, 2004, 2006b). Simmel concebe uma ideia de centralidade da esfera anímica na qual, determinada por relações sociais concomitantemente à consideração de seu núcleo individual, o cultivo resulta das próprias forças propulsoras da alma e preenche, assim, uma possibilidade prefigurada em si mesma.

O cultivo implica, portanto, a existência de algo, antes de sua ocorrência, em um estado não cultivado. Pressupõe também que a subsequente modificação desse sujeito esteja latente em suas relações estruturais ou impulsos anímicos, mesmo que ele não as possa realizar por si mesmo, mas apenas através da cultura. O cultivo guia o sujeito à perfeição que lhe é predeterminada nas tendências próprias e profundamente enraizadas em sua essência. Todo cultivo não é apenas o desenvolvimento de uma essência além do nível formal atingivel por processos naturais, mas também um desenvolvimento na direção de um núcleo originário, perfeição dessa essência segundo a norma de seu próprio sentido. Mas essa perfeição não é alcançável no estado denominado natural, consistente no desdobramento puramente causal das energias inerentes à essência. As possibilidades do homem enquanto ser cultural não são apenas o simples estado de forças de tensão latentes ou as reflexões e os acréscimos ideais de um espectador. Aquilo para que a alma pode evoluir em geral já reside nela, nos respectivos estágios, como linhas invisiveis nela desenhadas. O ser da alma humana, imbuído do dever e do poder da evolução, contém as possibilidades de evolução cujos objetivos residem exclusivamente na teleologia de sua própria essência - que por sua vez não

\footnotetext{
${ }^{4} \mathrm{O}$ cultivo pressupõe a consideração de um estágio cultural no qual a diferenciação entre sujeito e objeto tenham alcançado o status de objetividade. Pressupõe também a diferenciação da personalidade e o seu intercâmbio anímico e objetivo com formas culturais.
} 
pode atingir esses objetivos através do mero crescimento que the é interior, mas a partir de certo ponto é necessária uma técnica, um método volitivo.

Estrutura-se uma diferenciação íntima no processo cultural, ao passo em que o equivocado cultivo advindo da civilização ${ }^{5}$ somente acresce à alma um sistema de finalidades que lhe é estranho e desprovido de qualquer préformação nas tendências de sua própria essência. Portanto, o processo da cultura "[...] é o caminho que sai da unidade fechada, passando pela pluralidade desenvolvida, chegando à unidade desenvolvida" (SIMMEL, 2006b, p. 78), levando à realização do ser completo e peculiar que lhe é predeterminado e inicialmente existe apenas como possibilidade. Neste sentido, o cultivo é um processo infinito, pois o emprego de momentos objetivos para a perfeição do ser pessoal nunca pode ser considerado algo concluso.

Daí advém sua esfera trágica - ou, talvez o mais apropriado, deva-se entender o trágico não no sentido adjetivo, mas sim como um substantivo, visto ser essa tragicidade a condição elementar da cultura em Simmel. Ela consiste no princípio de estranheza imperante entre o processo da vida e de criação da alma, por um lado, e de seus conteúdos e constructos, por outro. Em contraposição à vitalidade e ao dinamismo da alma criadora está seu produto fixo, idealmente irremovível, cuja ação fixa retroativamente a primeva vitalidade da alma e a imobiliza; a alma experimenta a imobilidade no processo próprio da exteriorização e na objetivação das possibilidades pré-figuradas nela mesma. Ou seja, a dialética cultural alheia-se da sintese, uma vez que os constructos objetivos da alma, em seu próprio parto, distanciam-se dos sujeitos. O distanciamento, por sua vez, entre o sujeito e o objeto advém da natureza distinta da vida anímica, infatigável, e de suas formas objetivas, cristalizadas; a lógica interna, segundo a qual cada um deles se desenvolve, não coincide de maneira alguma com a do outro.

Portanto, a objetivação do impulso anímico subjetivo gera o seu encadeamento em uma série cultural na qual o seu desenvolvimento e possibilidade de ressubjetivação abandona o processo que o originou. $O$

\footnotetext{
5 Sobre o sentido da contraposição entre cultura e civilização na história intelectual germânica, ver Ringer (2000) e Norbert Elias (1994).
} 
ingresso de um constructo cultural numa ordem objetiva pressupõe a necessidade, por sua lógica distinta, de um arcabouço de proposições que definam e qualifiquem essa objetividade em seus termos próprios. Emerge daí a diferença entre o significado puramente objetivo e o significado cultural dos constructos. O nivel de isolamento da espiritualidade subjetiva contida em um constructo objetivo e sua relação reflexiva com a subjetividade dos sujeitos visando a centralidade de suas almas determina seu significado cultural - portanto, adentram na ordem dos valores culturais. Ao passo que o significado objetivo reduz-se ao encadeamento, numa ordenação objetiva, existente para si e regida por seus próprios imperativos, dos constructos culturais, alheados da teleologia idiossincrática dos sujeitos. Nasce uma tensão: percebe-se, segundo a diferenciação conceitual dos significados, que nos constructos objetivos da cultura o seu sentido e valor próprios tampouco coincidem com seu valor cultural; como formações objetivas, esses produtos do espírito não se preocupam com sua significação cultural ${ }^{6}$. Na medida em que

[...] certos motivos iniciais do direito, da arte e da moral são criados, já não controlamos mais para que tipo de formação específica eles se desenvolvem; ao criá-los ou recebê-los, percorremos antes o fio condutor de uma necessidade ideal, que é completamente objetiva e não menos despreocupada com as exigências de nossa individualidade do que as forças físicas e suas leis. (SIMMEL, 2008, p. 95-96, grifo nosso).

A autonomização dos conteúdos e sua subsequente existência autônoma é, para Simmel, a condição elementar da cultura que se repete incessantemente na manifestação de seus processos. Porém, na modernidade eles se intensificam. A concatenação da realidade social na modernidade se dá pela produção, reprodução e choque de lógicas autônomas estruturando um processo de objetivação conflituosa, de forma que os valores daí advindos resistem à acomodação numa ordem cultural. A

\footnotetext{
${ }^{6}$ Um exemplo desse embate entre significados distintos pode ser lido em: "Um nascer do sol que não é visto por nenhum olho humano não acresce absolutamente valor ao mundo, nem o torna mais sublime, uma vez que sua facticidade objetiva prescinde dessas categorias; mas tão logo um pintor reproduza a atmosfera, o sentido da forma e da cor e a capacidade de expressão deste nascer do sol em um quadro, passamos a considerá-lo um enriquecimento, uma elevação de valor da existência em geral. [...] Tanto o nascer do sol natural como a pintura existem como realidade; mas aquele só encontra seu valor na percepção do sujeito psíquico, ao passo que nesta, que já absorveu em si aquela vida e a configurou em um objeto, nossa percepção de valor para em algo definitivo, que prescinde de qualquer subjetivação.” (SIMMEL, 1998, p.88).
} 
obra de arte reivindica sua perfeição segundo a medida das demandas puramente artísticas; a pesquisa cientifica reclama sua legitimidade segundo a validade de seus resultados; o produto comercial, apenas segundo o fabrico mais adequado e sua valorização econômica mais lucrativa. A divisão do trabalho, bem como o desenvolvimento da razão instrumental dão bases a esse processo. Os conteúdos nos quais o eu deve executar a organização dinâmica de seus componentes anímicos e sociais visando a objetivação de um mundo unitário não são um domínio exclusivo do eu; eles the são dados por uma instância espacial, temporal e idealmente exterior. Eles são ao mesmo tempo os conteúdos de algum outro mundo - social e metafísico, conceitual e ético -, e nesses mundos eles possuem entre si formas e conexões que não coincidem com as do eu. Nesses conteúdos que configuram o eu, os mundos exteriores agarram o eu para incorporá-lo a si. $\mathrm{Na}$ medida em que eles formam os conteúdos segundo suas exigências, eles não permitem que os conteúdos tenham um centramento em torno do eu ou seja, os conteúdos em questão desligam-se de seu significado cultural.

Um exemplo disso é o conflito religioso entre a autossuficiência e a liberdade do homem e a sua inserção nos imperativos divinos. Mas este exemplo representa somente um caso daquele dualismo puramente formal, no qual o pertencimento de nossos conteúdos de vida a outros círculos além do nosso eu envolve inevitável e faticamente. Outro problema figura na análise: mediante a atuação anímica de um grupo de sujeitos surge um objeto cultural objetivo que, como totalidade e unidade, com um efeito específico, não tem nenhum produtor; ele não provém da correspondente unidade de um sujeito anímico. Os elementos reuniram-se segundo uma lógica e intenção de formação - não atribuídas a eles por seu criador interior a eles como realidades objetivas. Advém que as possibilidades de autonomia do espírito objetivo somente demonstra que ele, mesmo onde foi criado a partir da consciência de um espirito subjetivo, após a objetivação, possui uma apartada validade daquele espírito subjetivo e uma possibilidade independente de ressubjetivação. Em outros termos, a preocupação de Simmel é a relação entre a forma da individualidade, permeada pelo universo subjetivo, e a forma cultural-institucional dos constructos humanos, 
inserida em uma cadeia de significados culturais. De forma sintética: a trágica elementaridade da cultura e, principalmente, da época moderna sustentada pela intensificação da técnica em todas as esferas e a insatisfação que se apresenta para com ela - decorre do fato de as coisas tornarem-se sempre mais cultivadas, mas só em menor grau os homens podem se tornar capazes de conquistar uma completude da vida subjetiva a partir da perfeição dos objetos.

Delimitado o sentido dual e tensionado pelo conflito da cultura objetiva e da cultura subjetiva, cabe analisar sua relação conceitual com a crítica à objetividade do conhecimento. O conhecimento é para Simmel um constructo artificial que, através de uma linguagem logicamente articulada, é capaz, pelas relações conceituais, de alcançar representações parcialmente fiáveis de uma parte da realidade - o objeto em questão. O processo subjetivo de apreensão, através da linguagem, de um conteúdo objetivo objetividade que por sua vez engendra uma longa e imemorial cadeia de causas e efeitos cósmicos, biológicos e culturais - e seu subsequente cultivo, pelo indivíduo, revela um descompasso primordial.

A objetividade cultural do mundo, manifesta em estruturas e instituições sociais tais como o parentesco, a linguagem, a família, a religião, a arte etc. é um processo cultural que funde o tempo e o espaço em uma síntese sui generis, permeando simbolicamente a vida dos homens através da história. O passado de tais constructos culturais é tão importante quanto inapreensivel em sua totalidade, fazendo do homem seu partícipe com uma disparidade de natureza quantitativa e qualitativa elementar. Pois o significado e a relação dos conteúdos práticos e objetivos do mundo, ideal e empiricamente separados do indivíduo no qual se realizam, geram desde si mesmos a necessidade de determinados modos de conduta. Ou seja, o processo de diferenciação cultural que remete à extensão infinita dos constructos objetivos da cultura independe, apesar de sua realização se dar pelos homens, parcialmente deles. No mundo moderno os conteúdos do conhecimento, imersos em um processo de diferenciação crescente que propicia o surgimento de novos conceitos e áreas de conhecimento, ultrapassam a capacidade subjetiva de apreensão pelos indivíduos. O refino 
das instituições sociais e das estruturas objetivas que geram laços de solidariedade social está além da capacidade de ressubjetivação dos indivíduos. Aparentemente forma-se um domínio opressor, de uma cultura objetiva que asfixia as potências criadoras do homem. Porém, ao asfixiarem o homem por, por exemplo, sua discrepante idade, as instituições sociais e estruturas objetivas do mundo possibilitam também um processo envolvendo a ressubjetivação da objetividade que gera, num vagar de tartaruga, novas formas objetivas. O processo cultural, nessa dialética sem sintese, excetua o homem do jugo unívoco da natureza, pois faz dele não somente um mero descendente das formas culturais, mas sim um herdeiro de formas que, apesar de sua normativa objetividade e aparente cristalização, transformam-se, em um ritmo lento, no devir histórico.

A crítica à objetividade do conhecimento é o substrato meta-teórico que permite a compreensão da vida e da cultura em termos de uma disparidade imanente e insolúvel existente entre o status da vida e o status da conceitualidade, ou das formas culturais. Ou seja, a linguagem, um constructo objetivo dinâmico que estrutura tanto o mundo objetivo quanto as categorias sensiveis de apreensão dos indivíduos, é, ela mesma, uma forma, cujas imbricações foram acima descritas. $O$ conhecimento, estruturado pela linguagem, é também uma forma, e talvez a mais emblemática no processo de autonomização das formas culturais: as correntes intelectuais são a expressão adequada das capacidades e aspirações de um determinado período, fixadas objetivamente na esfera pública, cujo processo interno remete à justificação discursiva de suas proposições em seus próprios termos. Portanto, a crítica à objetividade do conhecimento pode ser encarada tanto como uma sintese teórica concebida pelo maduro Simmel, como uma temática que aparece fragmentariamente estruturada ao longo de sua teoria, mas uma estruturação que implica a consideração de suas pré-figuradas possibilidades: a história, compreendida por Simmel (2011c, p. 112) enquanto a sucessão das formas culturais e seu imanente conflito é somente a expressão de uma vida que sempre quer mais vida. 


\section{Individualidade e individualismo: a duplicidade que ascende à unidade}

A disparidade quantitativa e qualitativa existente entre vida e forma, a substância da crítica ao conhecimento, é nessa análise também o ponto de incursão à temática do individualismo em Simmel. O cerne da questão é, uma vez mais, a relação entre sujeito e objeto. Simmel (2001, 2003, 2006, 2007, 2011d) analisa o sentido do individualismo em seu desenvolvimento histórico, segundo uma perspectiva evolucionária de formas culturais. Caracteriza-o segundo um minimo conceitual, extraindo-lhe a forma essencial que, mediante a história e a ação do espírito humano, é moldada sob diversas formas, cada uma filha e herdeira de seu tempo. Essa forma, por sua vez, expressa o princípio da individualidade como a dupla condição inerente ao indivíduo: ele é um mundo centrado em si, porém, também é parte do universo social. Estrutura-se uma tensão, cujo significado é,

[...] por uma parte, certa relação em respeito a um mundo - mais ou menos amplo -, uma relação prática ou ideal, de rejeição ou concordância, de dominação ou servidão, de indiferença ou paixão. Por outra, não obstante, indica que essa natureza constitui um mundo por si mesmo, centrado em si mesmo e, em certa medida, encerrado em si mesmo e autossuficiente. A existência terrena inscreve nessa duplicidade toda natureza espiritual que possa em geral ser qualificada de "una": esta, segundo sua forma ou seu conteúdo, é algo por si mesma, uma unidade e tem uma realidade, um sentido ou uma meta que, em certa medida, repousam em si mesmos. Porém, simultaneamente, é parte de um ou de vários todos; está em relação com algo fora de si, uma totalidade abarcadora que a transpassa. Sempre é membro e corpo, parte e todo, plenitude e necessidade de completude. Chamamos individualidade a forma na qual esse duplo significado da existência humana consegue, ou intenta, acender à unidade, algo que pode muito bem efetuar-se segundo uma ampla gama de graus e nuances. (SIMMEL, 2003, p. 126-127, grifo nosso).

A individualidade é um duplo impulso cuja ascendente unidade se objetiva conflituosamente na figura do indivíduo. Dessa disposição geral, o centramento do eu concomitantemente a sua inserção em cadeias de sentido coletivo, decorre o conteúdo prático do dever. O dever é, por sua vez, a expressão de certas relações ontológicas de índole empírica e científica: ele é o nome do aspecto prático que a relação entre a individualidade e o universo social possui para o indivíduo, expressando a tensão existente entre a individualidade e sua submissão a constructos culturais objetivos alheios e desligados do centro anímico do eu. Simmel (2003, p. 72) atrela ao aspecto 
prático do dever sua significação substantiva: a vida, essa totalidade inimiga da forma, somente pode ser conhecida segundo o que ela foi, o que ela é e o que ela deverá ser, ou seja, o dever, nesse sentido geral, é uma disposição que envolve a possibilidade de objetivação de caracteres prefigurados em um processo cujo fim é indeterminado até o momento mesmo de sua realização. Restringindo-nos à esfera humana, o dever é a "dobradiça conceitual" (HABERMAS, 2012, p. 17) que une a individualidade à sua significação contextual; a individualidade, ela mesma propiciada por relações sociais, forma-se e se nutre em um contexto de formas culturais que se sucedem entre si. Ou seja, para se desenvolver a individualidade necessita de meios culturais e afetivos ausentes de suas prefigurações; um homem nasce bebê, reconhecido no seio familiar por sua própria carência, que por sua vez transmuta-se, lentamente, em autonomia à medida que formas culturais, tais como a linguagem, a comunicação, o idioma, os sistemas de valores etc. estruturam objetivamente a percepção do sujeito, o qual, por sua vez, interpreta os conteúdos culturais e age no mundo segundo uma desproporcional medida de formas culturais, herdadas de um processo imemorial, e os processos psíquicos individuais que elaboram idiossincraticamente um projeto biográfico - essa temática será retomada à frente.

$\mathrm{Na}$ caracterização do individualismo dois polos analíticos erigem-se. O primeiro refere-se à delimitação conceitual do sentido da individualidade (o contorno conceitual da dual constituição da vida humana: ser, em si, um mundo e, concomitantemente, ser parte de um mundo) e seu aspecto prático, a tensão ontológica do dever. O segundo refere-se aos processos sociais nos quais, através das forças objetivas da cultura, estrutura-se a ascendência objetiva dessa dualidade na figura histórica do indivíduo. Dessa segunda perspectiva advém a concepção de Simmel de duas formas distintas de individualismo na modernidade. A partir do século XVIII, numa confluência de determinações entre processos empíricos (emergência de uma economia de mercado monetarizada, divisão do trabalho, urbanização, diferenciação social crescente) e correntes e principios intelectuais (grosso modo, o humanismo do Renascimento, a "lei natural" do século XVII, a 
filosofia de Kant e a construção objetiva do eu), o eu ou a personalidade emerge como um conceito central: por um lado, toda a existência se apresenta como uma ideia criadora de um eu consciente e, por outro, a personalidade e seu desenvolvimento torna-se um objetivo.

Daí as formas distintas de individualismo. O século XVIII pariu o individualismo quantitativo, e o século XIX, o individualismo qualitativo. O século XVIII caracterizou-se pelo ideário da natureza em suas manifestações intelectuais e, corolário disso, o conhecimento orientava-se às ciências naturais. Essa inclinação evidenciou-se pela busca de um conceito universal, uma lei geral e natural da qual toda manifestação individual fosse seu epifenômeno (KOYRÉ, 1979, p. 131). Simmel situa em Kant (2008) o mais elevado nível dessa discussão; o ser humano individual era a essência do ser humano universal, situado na mesma medida em todos os seres - o homem abstrato. Porém, esse ser geral foi obscurecido pelas transformações e desvios históricos ${ }^{7}$ - e neste ponto reside a centralidade do conceito de liberdade nesse século. O sentido da individualidade reside na igualdade universal, dividida numa tríplice concepção: a igualdade perante a natureza, a igualdade perante a universalidade da razão e a igualdade da humanidade. A partir daí o homem constitui-se como ser autossuficiente, pois se o homem abstrato habita igualmente todos, mediante a igualdade plena anula-se a necessidade de uma regulação exterior ao verdadeiro eu, universal e portador da objetividade - a expressão de tal ideal é o autogoverno da liberdade positiva.

\footnotetext{
7 Simmel caracteriza esse obscurecimento nos seguintes termos: "[...] a precariedade das formas de vida socialmente válidas no século XVIII - tais como os privilégios das castas superiores, o controle despótico de comércio e circulação, os resíduos ainda poderosos das constituições corporativas, a coação impaciente do clericalismo, as obrigações da gleba dos trabalhadores rurais, a ausência de participação política na vida do Estado e as restrições das leis municipais - parecia, à consciência dos indivíduos, uma repressão insuportável de suas energias em relação às forças produtivas materiais e espirituais da época. Da repressão que operava por meio de tais instituições, que perderam toda legitimidade essencial, surgiu o ideal da simples liberdade do indivíduo. Bastava que caíssem aquelas amarras que obrigavam as forças da personalidade a trilhar caminhos antinaturais para que todos os valores internos e externos, todas as capacidades previamente existentes até então refreadas politica, religiosa e economicamente, se desenvolvessem e conduzissem a sociedade da irracionalidade histórica para a sociedade da racionalidade natural" (SIMMEL, 2006, p. 92).
} 
A confluência e determinação existente entre os processos empíricos e as correntes intelectuais é mais complexa no século XIX. Da fecunda pluralidade de correntes intelectuais desse século um substrato pode ser apreendido: restringindo-se à esfera humana, a ideia de sociedade foi proclamada pela primeira vez como a realidade vital do ser humano. Seguida à formalização da liberdade no século XVIII, com a subsequente igualdade substancial entre os homens, surgiu, no século XIX, a necessidade interna de diferenciação dos indivíduos. Alavancada pela objetividade do eu, essa diferenciação interna caracteriza o individualismo qualitativo. Não se trata mais - de encontrar o eu puro, mas sim o eu específico, que não se repete em nenhuma instância da natureza.

Os principios econômicos da concorrência e da divisão do trabalho são protagonistas no processo que aponta à mudança qualitativa e quantitativa da solidariedade social: as relações sociais reificam-se e se objetificam sob o imperativo da lógica econômica instrumental. Porém, da tendência à precarização e neologismo das relações sociais engendrada sistemicamente emerge a possibilidade da liberdade individual, pois, paulatinamente, a ação individual, através das estruturas impessoais do mercado, desliga-se cada vez mais das formas preexistentes restringindo-se, assim, à instantaneidade do presente. A liberdade nesse contexto não significa a oposição à dependência em relação a outros indivíduos, mas sim a independência em relação a qualquer indivíduo específico. O indivíduo torna-se livre na medida em que depende de outros indivíduos, visto a formação objetiva de círculos sociais atuantes por uma lógica expansiva, materializando relações sociais complexas e mediadas, mas, ao mesmo tempo, ele independe de qualquer individuo particular. A objetificação das relações sociais, caracterizada pela cisão das formas tradicionais de sociabilidade no seio comunitário, conjuntamente a seus pressupostos de identidade, personalidade e afeto tomados enquanto caracteres imanentes do tráfego mercantil e nas relações inter-pessoais, torna-se a estrutura social da modernidade. A objetificação das relações sociais conduz, portanto, a um tipo de solidariedade social que não mais se dirige através do homem: ele é mediado pelas funções e pelas coisas. 
Ao final de sua vida Simmel observa a concreção de uma gigantesca força cultural, nos termos de uma cultura objetiva que, por sua elementar condição de disparidade com os processos vitais, ameaça a vida do indivíduo. Sua preocupação com o indivíduo é ambivalente. Primeiramente, ela aponta à consideração metodológica das relações, visto o indivíduo moderno ser formado por relações sociais complexas. Em segundo lugar, ela aponta ao aprofundamento dessas relações em um contexto social de hipertrofia cultural, ou seja, um contexto no qual as forças da cultura objetiva sobrepujam, em muito, a vitalidade e as potencialidades da vida individual. Neste ponto é necessário retomar a argumentação acima exposta.

Novamente na esteia dos problemas presentes no texto A lei individual, Simmel deixa transparecer sua preocupação com o indivíduo a partir de um problema estrutural. Além dos condicionamentos objetivos das estruturas sociais sob o indivíduo, figura também a determinação moral. O ponto de Simmel, uma vez mais, é a crítica do imperativo categórico kantiano e a subsequente vinculação conceitual existente entre o dever e a lei universal, pois nessa perspectiva o dever origina-se em um esquema ideal previamente fixado. A lei é, por ela, universal segundo seu próprio conceito, já que todo o eticamente preceptivo ou proibitivo deve derivar de conteúdos que subsistem por si mesmos em virtude de sua lógica autônoma.

Como já dito, Simmel considera ser o dever a expressão de certas relações ontológicas, portanto fáticas, o que o leva a atrelar conceitualmente o dever à dinâmica interna da vida. O enraizamento do dever moral na totalidade de cada vida particular entranha uma objetividade mais radical que o moralismo racional pode alcançar. As leis universais, cuja formulação abstrata reside no imperativo categórico, não podem dar forma à obra humana atendendo à sua inserção real na vida. O dever não se deduz em absoluto de um fim, afastando-se de um processo teleológico; ele é um processo vital, e não a irradiação abstrata de conteúdos. Erige-se o papel central da responsabilidade, uma vez que a temática da cultura em Simmel pressupõe um homem portador da cultura, estruturado pela responsabilidade individual e social (KRACAUER, 2009, p. 251). 
Nessa perspectiva, a ética empenha-se em conciliar (pois resolver é uma palavra demasiadamente ambiciosa) a elementar tragédia do indivíduo - a dualidade da estrutura vital individual, ou seja, uma vida inserida em um contexto social. Simmel reivindica a vitalidade, pois mesmo quando exigida a ação particular pelo seu próprio significado, segundo seu conteúdo, faltar-lhe-á a vinculação plena, genético-ideal com a vida total de seu executor, e a responsabilidade não encontrará nenhum fundamento unitário. Também, mesmo que os conteúdos do dever provenham do âmbito da totalidade da vida, a decisão mesma acerca desses conteúdos não pode se efetuar a partir deles mesmos nem de fins e normatividades particulares; ela é reservada à unidade e continuidade da vida. Daí Simmel afirmar: "[...] o dever é, em cada caso, uma função da vida total de uma personalidade individual" (SIMMEL, 2006, p. 74). Pois cada ato ocasional reflete não um fragmento, mas a totalidade da vida, com sua infinita combinação processual de causas e efeitos. A coesão interna da vida é, assim, compacta, pois ela está inteiramente em cada um dos indivíduos de forma tão peculiar que com ela também veem circunscritas tanto a separação qualitativa entre uns e outros como a clausura sem pontes até os demais, de cada indivíduo particular. A lei individual - ao contrário da universalidade racionalista - é, portanto, a contraposição teórica à legitimação moral externa à vida, pois como brada Simmel, o dever moral deve brotar da vitalidade da mesma, na confluência de seus processos com a centralidade anímica do indivíduo.

A lei individual pode ser compreendida como a sintese entre a crítica à objetividade do conhecimento e o individualismo, pois ela remete à disparidade existente entre vida e forma; desse embate Simmel intenta conduzir o dever moral ao núcleo vital da vida, ou seja, a lenta fluência dos acontecimentos a partir da centralidade anímica da alma e seu desenvolvimento. Dessa maneira o dever moral coaduna da vitalidade da vida, e não se origina em um esquema objetivo pré-figurado. É claro que esse tema vai ao encontro da abissal desproporcionalidade de ação individual frente à cultura objetiva. Porém, na coesão interna do pensamento de Simmel ele não implica contradição, como facilmente poderia se argumentar mediante o simplista comodismo intelectual de anular a perspectiva 
individual frente à cultura objetiva que se desenvolve independentemente de certas ações humanas.

O cerne da questão é que Simmel (1955, 2005 2006, 2006b, 2011d) compreende a época moderna como a maior disseminadora de tendências opostas jamais vista. As dinâmicas das estruturas objetivas da cultura são marcadas pela autorreferencialidade, o que na modernidade implicou, através da diferenciação social crescente, a vertiginosa ascensão de mundos sociais distintos, sustentados por variados estilos de vida (SIMMEL, 2011d, p. 402) e regidos por lógicas heterogêneas, conflitivas e mesmo irreconciliáveis. Os estilos de vida apontam aos processos de diferenciação cultural e social segundo a tensionada relação entre sujeito e objeto. A dualidade fática que envolve a consideração particular de uma vida e sua inexorável inserção no cosmos social através de constructos culturais está implícita nos estilos de vida por sua própria significação semântica: Simmel utiliza a significação de estilo, tomada de empréstimo da história da arte e da filosofia, como o "revestimento de um conteúdo (exornatio)" e, concomitantemente, como a "encarnação de um conteúdo (incarnatio)" (RAMMSTEDT, 2015, p. 61). Ou seja, o estilo de vida é, ao mesmo tempo, um conteúdo cultural revestido por um projeto biográfico idiossincrático, por sua vez composto pela individualidade e sua tensão ontológica, e o processo em si de objetivação cultural de determinados impulsos anímicos e sua consequente ressubjetivação individual. Portanto, os conteúdos objetivados no processo cultural nutrem, viabilizam e constringem a vida individual em um cosmos social caracterizado pela heterogeneidade valorativa. Nesses distintos mundos valorativos integram-se os indivíduos, com a vitalidade de suas vidas seccionada pelos constructos culturais que, por sua vez, proporcionar-lhe-ão o cultivo a partir - o que, na modernidade, aponta a um imperioso ou não - de sua centralidade anímica.

Dessa forma, reflexo e corolário das tendências opostas que estruturam a realidade social na modernidade, a análise de Simmel transita entre momentos analíticos opostos, paradoxais e ambivalentes. Simmel reclama a vitalidade da vida de tal forma que a cultura se realinhe ao seu nicho vital; porém, a vitalidade estrita rechaça a forma, e não há significação 
cultural sem formas. O indivíduo nasce no interior da cultura, em um contexto imemorial de formas culturais que se mutam no devir histórico; porém, a agência individual é constringida pela inflacionária cultura objetiva, de forma a estar sempre aquém desta. Simmel apreende o individualismo segundo a diferença que suas formas assumem, portanto, a centralidade da análise está em compreender dinâmicas sociais. Mais especificamente, Simmel compreende, através do individualismo enquanto expressão, o conflito interno da cultura que se diferencia na eterna luta entre a vitalidade da vida e sua cristalização na forma. Mas esse também é o substrato da crítica ao conhecimento, o que nos leva a melhor caracterizar o vínculo conceitual existente entre ela e o individualismo.

O acento do Simmel crítico em relação à objetividade do processo interno e às formas do conhecimento está no fato deste reconstruir a realidade segundo um princípio a ela alheio. Nessa perspectiva, no estudo do individualismo, o que a análise de Simmel alega é o exame dinâmico da mutação das formas do individualismo, sustentadas empiricamente por uma estrutura social objetiva, e não um exame ontológico que se limita ao alvitre intelectual de inferir a realidade social ou a partir dos individuos ou a partir da esfera coletiva. As dinâmicas sociais objetivam-se por relações; ou seja, a primeva assunção metodológica de Simmel é apreender a aparente unicidade dos objetos através da análise de suas relações, revelando o processo social no qual ele está inserido e sua característica forma. Essa assunção implica a complexa configuração da vida, por sua vez irredutivel de forma total aos conceitos, e uma composição dinâmica de perspectivas analíticas que possam deslindar a aparente unicidade das teias de significados culturais.

Simmel intenta um exame reflexivo do conhecimento que, mesmo em situações de uma análise empírica pontual, não descarta uma risada galhofeira, cujo sentido último é explicitar que sempre a realidade estará além das teorias, exaltando um portentoso e inabalável ponto de interrogação contra as tímidas e insuficientes pretensões intelectuais humanas. No individualismo essa característica aparece na consideração de Simmel (2006, p. 71) acerca da irracionalidade e irredutibilidade que a esfera intima e vital, porém inalcançável, da vida individual revela, pese toda a 
sorte de determinismos culturais que retroagem sobre a psique do individuo, além de uma consideração metodológica substancial: "A linha divisória que culmina no 'indivíduo' também é um recorte totalmente arbitrário, uma vez que o 'individuo', para a análise ininterrupta, apresenta-se necessariamente como uma composição de qualidades, destinos, forças e desdobramentos históricos específicos que, em relação a ele, são realidades elementares tanto quanto os indivíduos são elementares em relação à 'sociedade'." (SIMMEL, 2006, p. 13). Mas essa característica repete-se também no cosmos social, com a concreção de uma cultura objetiva que sobrepuja as forças do indivíduo. Uma vez mais, o que se depreende nos apontamentos de Simmel não é a contradição, mas o princípio substancial de seu pensamento - e uma característica empírica da modernidade -, a infinita extensão e tensão de tendências opostas.

A vida individual é limitada, de antemão, por uma curta temporalidade, à medida que estruturas objetivas e instituições sociais elementares ao homem, tais como o idioma, o sistema de parentesco, a família, a estrutura grupal, comunitária e societária etc. são milenares. O forte acento dado ao indivíduo por Simmel também deriva das condições estruturais da modernidade que, além do fomento à liberdade individual, ameaçam a vitalidade dessa vida pela sua lógica autorreferencial e pela produção e reprodução infinita de conteúdos culturais, cuja ressubjetivação pelos indivíduos está aquém de seu desenvolvimento. Portanto, a individualidade em Simmel aponta para a objetivação idiossincrática, através de um processo psíquico individual, de modos de sensibilidade e de conduta que estruturam um projeto biográfico inserido em um amplo contexto cultural, por sua vez causa e consequência do indivíduo, ao passo que o individualismo é a expressão da dualidade ontológica objetivada na figura histórica do indivíduo.

\section{Considerações finais}

A crítica à objetividade do conhecimento é um ponto de incursão ao universo heurístico, gnosiológico e metodológico de Simmel. As negativas críticas que tentaram minimizar e deturpar em um sentido alheio o 
pensamento de Simmel somente erigiram as bases dinâmicas de compreensão de sua teoria. A crítica à objetividade do conhecimento possui dois significados. O primeiro é o significado pontual, que remete à explanação crítica de Simmel à natureza do conhecimento em seu desenvolvimento lógico. Ou seja, o conhecimento objetivo é sustentado por um método, limitado de antemão, que permite deslindar uma parte - o objeto em questão - da realidade segundo um discurso logicamente justificado. Sustentado pelos conceitos, em si mesmos uma forma de ordenação e de imposição de significados artificialmente relacionados, o conhecimento objetivo opera através da secção e do isolamento da ininterrupta fluência que se dá em e entre as coisas em unidades de sentido lógicas, na correlatividade relacional infinita que objetiva a realidade em um nível cósmico, biológico e social - para Simmel, conhecer a realidade, ainda que um conhecimento seletivo e fragmentado, é reconhecer relações. A principal questão nessa problemática é a disparidade existente entre a vida, em sua impossivel apreensão total pelo conhecimento, e as formas, em seu apartado e distinto mecanismo de existência. A crítica à objetividade do conhecimento possui uma lógica que distingue, a priori, a vida em sua vitalidade do conhecimento mediado que se faz dela: a vida torna-se autoconsciente quando ela apreende reflexivamente sua vitalidade, apreensão por sua vez realizada com o auxílio de formas culturais objetivas que permitem e estruturam a intelecção do mundo por um sujeito cognoscitivo.

O significado contextual remete à relação teórica da lógica da crítica à objetividade do conhecimento com os centrais temas da cultura e do individualismo. A cultura em Simmel remete à tensão existente entre a cultura subjetiva, marcada pela centralidade anímica da alma criadora, e a cultura objetiva, o produto fixo e parcialmente cristalizado daquela primeva consciência, mas detentor de uma autonomia tanto em relação a quem o objetivou quanto aos possiveis outros sujeitos que atuarão em sua ressubjetivação em função de um status de existência diferenciado. Essa tensão, uma substantiva tragédia, origina uma dialética cultural sem síntese que erosiona crescentemente a relação entre a subjetividade e os constructos culturais, produzidos e reproduzidos em uma desproporcional relação de 
objetivação e ressubjetivação. Portanto, a tensão da cultura origina-se justamente na diferenciação de status entre a vitalidade da vida e as formas culturais, o substrato lógico da crítica à objetividade do conhecimento.

A diferença quantitativa e qualitativa entre a vitalidade e as formas, ao atravessar a cultura, deságua no individualismo. Pois a figura histórica do indivíduo, sustentada pela duplicidade ascendente à unidade - o ser específico e sua inserção em cadeias de sentido coletivas - da individualidade, desenvolve-se no interior de um contexto cultural de hipertrofia objetiva. A centralidade anímica do eu, pela carência de meios inatos de desenvolvimento, desenvolve-se através do cultivo, o que implica a mediação de constructos culturais objetivos formadores. Tais constructos não possuem, via de regra, uma estrita congruência com a centralidade anímica; ao contrário, o projeto biográfico é formado pelo eu na introjeção de motivos objetivos alheios à idiossincrasia individual - os constructos culturais, albergados em uma ordem e em valores culturais possibilitam, moldam e constringem a vida individual no interior de formas distintas (comunicação, linguagem, ética, moral, educação, sistema de valores etc.). A isso soma-se a fática condição ontológica do dever e sua importância vital. A vida social, enquanto vida cultural, remete à trágica elementaridade de descompasso entre a vitalidade e as formas, entre a individualidade e as exigências sociais objetivas da vida prática e de sua vertente cultural e institucional - em outras palavras, a vitalidade da vida é seccionada na cultura, e a partir dessa descontinuidade, através da objetividade do conhecimento, intenta sintetizar um processo naturalmente inconcluso.

O ponto comum dos dois significados expostos é a lucidez de Simmel. A crítica à objetividade do conhecimento não o desqualifica (Simmel não concebe a modernidade sem os constructos da ciência e suas ambivalentes potencialidades); antes, o situa em uma arena reflexiva concernente a suas limitações fundantes. O conhecimento objetivo não deslinda a realidade como um espelho fiel; antes, através da mediação científica, somente o que é passivel e possivel de ser captado pelo método pode figurar nessa realidade ao caráter extensivo e quantitativo do conhecimento objetivo corresponde o caráter intensivo e qualitativo que a realidade social lega dinamicamente. 
Descobrir a encadeação lógica dos componentes de uma parte do universo (cósmico, biológico ou social) a ser conhecida não implica a estrita generalização de que o universo em questão em si seja lógico; a lógica é somente uma parte desse universo, cujo parcial conhecimento é limitado pelas carências do método científico. Há, portanto, a partir do significado que essa crítica assume, um ensejo objetivo para se pensar na preocupação de Simmel, no começo do século XX, com diferentes formas de pensamento e conhecimento que não o cânone da ciência ocidental. Afinal, o conhecimento está sempre aquém de uma vida que sempre quer mais vida.

\section{Referências}

ADORNO, Theodor W. Notas de Literatura I. São Paulo: Editora 34; Livraria Duas Cidades, 2008.

ARON, Raymond. Main currents in sociological thought. Nova York: Basic Books, 1967.

BACKHAUS, Gary. Georg Simmel as an eidetic social scientist. Sociological Theory, New York, v. 31, n. 2, p. 260-281, 1998.

BECK, Ulrich. A reinvenção da política: rumo a uma teoria da modernização reflexiva. In: BECK, Ulrich; GIDDENS, Anthony; LASH, Scott. Modernização reflexiva. São Paulo: UNESP, 2012.

COLLINS, Randall. Four sociological traditions. Nova York: Oxford University Press, 1994.

COSER, Lewis. The functions of social conflict. Glencoe: Free Press, 1956.

ELIAS, Norbert. O processo civilizador. Rio de Janeiro: Zahar, 1994.

FRÉULER, L. La crise philosophique au XIXe siècle. Paris: Vrin, 1997.

FREUND, Julien. Introductionà Georg Simmel: Sociologie et épistémologie. Paris: PUF, 1981.

FRISBY, David. Sociological impressionism. A reassessment of Georg Simmel's social theory. New York: Routledge, 2013.

GIDDENS, Anthony. A vida em uma sociedade pós-tradicional. In: BECK, Ulrich; GIDDENS, Anthony; LASH, Scott. Modernização reflexiva. São Paulo: UNESP, 2012.

GROETHUYSEN, Bernard. Introduction à la pensée allemande depuis Nietzsche.Paris: Librairie Stock, 1926. 
HABERMAS, Jünger. Sobre a constituição da Europa. São Paulo: UNESP, 2012.

HELLE, Horst J. Messages from Georg Simmel. Chicago: Haymarket, 2014. HOBSBAWM, Eric. Sobre História. São Paulo: Companhia das Letras, 2013. Era dos extremos: o breve século XX: 1914-1941. São Paulo: Companhia das Letras, 1995.

KANT, Immanuel. Metafisica dos costumes. Bauru, EDIPRO, 2008.

Oeuvres philosophiques. Paris: Gallimard, 2004.

Critique de laraisonpure. Paris: PUF, 1950.

KOYRÉ, Alexander. Coisas que ninguém nunca viu antes e pensamentos que ninguém teve: a descoberta de novos astros no espaço físico e a materialização do espaço. In: Do mundo fechado ao universo infinito. São Paulo: Forense/Edusp, 1979.

KRACAUER, Siegfried. O ornamento da massa. São Paulo: Cosac \& Naify, 2009.

LEVINE, Donald. Georg Simmel: on individuality and social forms. Chicago: University of Chicago Press, 1971

Simmel as educator: on individuality and modern culture. Theory, Culture and Society, Londres, v. 8, n. 3, 1991.

2014.

Social theory as a vocation. New Jersey: Transaction Publishers,

Revisitando Georg Simmel. Sociologia \& Antropologia, Rio de Janeiro, v. 5, n. 1, 2015.

MOSSE, Georg L. La nacionalización de las masas: simbolismo político y movimentos de masas em Alemania desde las Guerras Napoleónicas al Tercer Reich. Buenos Aires: Siglo XXI, 2007.

PASTI, Henrique Buonani. As teorias da cultura em Georg Simmel: textos de 1889-1911. Dissertação de mestrado. Universidade Estadual de Campinas (UNICAMP), 2012.

POLANYI, Karl. A grande transformação. Rio de Janeiro: Campus, 1980.

RAMMSTEDT, Otthein. Como Georg Simmel chegou à Modernidade e lhe permaneceu fiel? Sociologia \& Antropologia, Rio de Janeiro, v. 5, n. 1, 2015. 
RINGER, Fritz K. O declinio dos mandarins alemães. São Paulo: EDUSP, 2000.

SIMMEL, Georg. Conflict. New York: Free, 1955.

1961.

Problemas fundamentales de la filosofia. México D. F.: UTEHA,

Simmel e a modernidade. SOUZA, Jessé; OËLZE, Berthold (orgs.). Brasília: Ed. UNB, 1998.

El individuo y la libertad. Barcelona: Ediciones Península, 2001.

. La ley individual y otros escritos. Barcelona: Paidós, 2003.

. Philosophie de la modernité. Paris: Editions Payot\&Rivages, 2004.

2006.

Questões fundamentais da Sociologia. Rio de Janeiro: Jorge Zahar,

La tragedie de laculture et autresessais. Paris: Rivages, 2006b.

- Imágenes momentâneas. Sub specie aeternitatis. Barcelona:

Editorial Gedisa, 2007.

. Filosofia da moda e outros escritos. Lisboa: Edições Texto \& Grafia, 2008.

El conflicto. Sociología del antagonismo. Madrid: Sequitur, 2010b.

2011.

Ensaios sobre teoria da história. Rio de Janeiro: Contraponto,

Ponte e porta: saggi di estetica. Bologna: ArchetipoLibri, $2011 \mathrm{~b}$.

Religião. v. 2. São Paulo: Olho d'Água, 2011c.

The Philosopy of money. New York: Routledge, 2011d.

SOROKIN, Pitirim. Contemporary sociological theories. Nova York: Harper \& Brothers, 1928.

SPYKMAN, Nicholas. The social theory of Georg Simmel. New Jersey: Transaction Publishers, 2004.

VANDENBERGHE, Frédéric. A philosophical History of German Sociology. New York: Routledge, 2009.

VON WIESE, Leopold. Sociologia: historia y principals problemas. Barcelona: Labor, 1932. 
WAIZBORT, Leopoldo. As aventuras de Georg Simmel. São Paulo: 34, 2011.

WATSON, Walter. The architectonics of meaning: foundations of new pluralism. Nova York: State University of New York Press, 1985. 